\title{
Effect of Processing on Amino Acid Profile of Balanites aegyptiaca Kernel
}

\author{
Muhammad Ibrahim Usman ${ }^{1 *} \quad$ Abubakar Bilyamini Mu'azu1 ${ }^{1}$ Ibrahim Ali Bukar ${ }^{2}$ \\ 1.Department of Medical Biochemistry, College of Medical Sciences, Yobe State University Damaturu, \\ P.M.B. 1144, Yobe. Nigeria \\ 2.Department of Human Physiology, College of Medical Sciences, Yobe State University Damaturu, \\ P.M.B. 1144, Yobe. Nigeria
}

\begin{abstract}
Balanites aegyptiaca kernel has been shown to have high nutritional quality as it is rich in both essential and nonessential amino acids. However, little is known on the effects of different processing methods on amino acid profile of the kernel. This research work therefore evaluates the effect of processing (boiling and soaking) on amino acid profile of the kernel using standard analytical methods. A significant $(\mathrm{p}<0.05)$ difference in amino acid contents between the raw and processed kernel was observed. Between the processed samples, boiled sample shows a higher amino acid contents than the soaked sample. Boiling retains the most nutritive value and therefore it should be encouraged as a means of processing for consumption.
\end{abstract}

Keywords: Amino acid profile; Boiling; Soaking; Balanites aegyptiaca; and Kernel

DOI: $10.7176 / \mathrm{JNSR} / 11-22-04$

Publication date: November $30^{\text {th }} 2020$

\section{Introduction}

Balanites are a genus of flowering plants in the caltrop family; zygophyllaceae founded in 1813 by Delile and has selected species which include Balanite aegyptiaca (Guinand and Dechassa, 2009). Banalites aegyptiaca is commonly known as desert date an important multipurpose tree found in most African countries. It is a woody evergreen xylophylic tree with a height of $10 \mathrm{~m}$ grown in various ecological conditions mainly distributed in semiarid zones in tropical Africa especially in Senegal, Sudan and also Asian countries such as India. Balanites aegyptiaca in English is known as desert date, soap berry tree bush, thron tree, Egyptian balsam or Zachum oil tree. In Arabic, it is known as lalob, hidjihi, inteishit and heglig (hijlig). In Nigeria, the plant is commonly found wild in Borno, Yobe and Adamawa States of north east region. It is known as Adowa in Yoruba, Aduwa in Hausa, Tanni in Fulfulde and cungo in Kanuri (Clementet et al., 2011).

Balanite aegyptiaca is one of the most common but neglected wild plant species of the dry land areas of Africa and South Asia. It has wide ecological distribution, but is mainly found on river banks in depressions with deep sandy loam and grows well in valleys and on the slopes of rocky hills. Balanites aegyptiaca fruit is edible but bitter and parts of the plants are used as famine foods in Africa, the leaves are eaten raw or cooked, the oily seed is boiled making it less bitter and eaten mixed with sorghum. The flowers could also be eaten. Its seed is the pyrene (Stone) part of Balanites aegyptiaca plant about 1.5-3cm long, light brown, fibrous and hard, making up to $50-60 \%$ of the fruit with about 500-1500 dry clean seeds $/ \mathrm{kg}$ (Chothani and Vaghasiya, 2011).

Various reports on the nutritional and anti-nutritional profile of Balanites aegyptiaca seeds powder has shown that the seed powder contains a relatively high amount of protein and lipids and some amount of anti-nutritional factors such as tannins, oxalate and phytic acid as compared to other plant products. Balanite aegyptiaca produces fruits which are edible, and the nutritive and calorific values of fruits make them necessary in diets, as they are natural source of food nutrients such as protein, carbohydrate, minerals and dietary fiber, needed by man and animals (Muhammad et al., 2018).

Food processing is a set of methods and techniques used to transform raw ingredients into food or food into other forms for consumption by humans or animals. Nearly all foods, whether derived from plant or animal sources, are rarely fit for direct consumption and require some prior processing. Methods of food processing have been developed over the centuries and are adopted apparently to make the final product more attractive in flavour, appearance, taste, and consistency. The common practices of processing foods include; milling, germination or sprouting, malting, fermentation, soaking and cooking, each of these processes qualitatively and/or quantitatively modifies the nutritive value of the food (Clement et al., 2011)

In a recent studies, Muhammad et al (2018) reported the presence of both essential and non-essential amino acids Balanites aegyptiaca kernel and therefore concludes that the kernel is of high nutritional value. However in most cultures, the kernel is processed prior to usage, this study evaluate the effects of processing methods on amino acid profile of the kernel. 


\section{Materials and Methods}

2.1 Sample Collection and Preparation

Balanites aegyptiaca fruits were obtained from Abubakar Rimi market, Kano Munincipal Local Government Area, Kano state Nigeria. It was authenticated at the department of plant biology Bayero University Kano, with an accession number BUKHAN0359. The fruit was processed by soaking in water for 48 hours, de-pulped. The seed obtained were hard cracked using a hammer to obtain its kernel. The kernels were divided into three portions of $200 \mathrm{~g}$ each, two of the three portions were processed through boiling and soaking respectively while the last portion was considered as control.

The boiling process was done by placing $200 \mathrm{~g}$ of the kernels in a cooking utensil with $900 \mathrm{ml}$ of water and boiled for 30 minutes at $100^{\circ} \mathrm{C}$. The supernatant was discarded and the boiled kernel was transferred into a glass bowl and placed in an oven to dry at $45^{\circ} \mathrm{C}$ to a constant weight. For the soaked sample, $200 \mathrm{~g}$ of the kernel was mixed with $500 \mathrm{ml}$ of distilled water in $1000 \mathrm{ml}$ conical flask and allowed to ferment naturally at room temperature for 48 hours. The supernatant was discarded and the boiled kernel was transferred into a glass bowl and placed in an oven to dry at $45^{\circ} \mathrm{C}$ to a constant weight.

The dried raw, boiled and soaked kernels were pulverized using a mortar and pestle. The pulverized sample was stored in plastic container for analysis.

\subsection{Analysis of Amino Acid Profile of Balanites aegyptiaca Kernel}

The sample was dried to constant weight, defatted, hydrolyzed, evaporated in a rotary evaporator (Benitez, 1989).It was then loaded into the Technicon Sequential Multi-Sample Amino Acid Analyzer (TSM).

\subsubsection{Defatting Sample}

Exactly four grams (4g) of the sample was weighed and inserted in an extraction thimble and extracted for 15 hours using soxhlet extraction apparatus with mixture of chloroform/methanol in ratio 2:1 (AOAC, 1997).

2.2.2. Hydrolysis of the sample

A known weight $(200 \mathrm{mg})$ of the defatted sample was weighed into glass ampoule, then $7 \mathrm{~cm}^{3}$ of $6 \mathrm{NHCl}$ was added and oxygen was expelled by passing nitrogen into the ampoule (this is to avoid possible oxidation of some amino acids during hydrolysis e.g methionine and cystine). The glass ampoule was then sealed with Bunsen burner flame and inserted in an oven preset at $105^{\circ} \mathrm{C} \pm 5^{\circ} \mathrm{C}$ for 22 hours. The ampoule was allowed to cool before broken open at the tip and the content was filtered to remove the humins. The filtrate was then evaporated to dryness in hot air oven, the residue was dissolved with $5 \mathrm{~cm}^{3}$ of acetate buffer ( $\left.\mathrm{pH} 2.0\right)$ and stored in plastic specimen bottles, which were kept in the freezer as a hydrolysate.

2.2.3. Loading of the hydrolysate into TSM analyzer

The amount of hydrolysate loaded $(10 \mu 1)$, this was dispensed into the cartridge of the analyzer. The TSM analyzer is designed to separate and analyze free acidic, neutral and basic amino acids of the hydrolysate. The period of analysis lasted for 76 minutes. An integrator attached to the analyzer calculates the peak area proportional to the concentration of each of the amino acids.

\section{Results}

Figure 1 presents the essential amino acid composition of raw and processed Balanite aegyptiaca kernel. Significant $(\mathrm{p}<0.05)$ difference existed between the raw and processed kernel and also between the treated sample. The result revealed the presence of nine essential amino acid. Two amino acid were absent (asparagine and glutamine) in both raw and processed sample. 


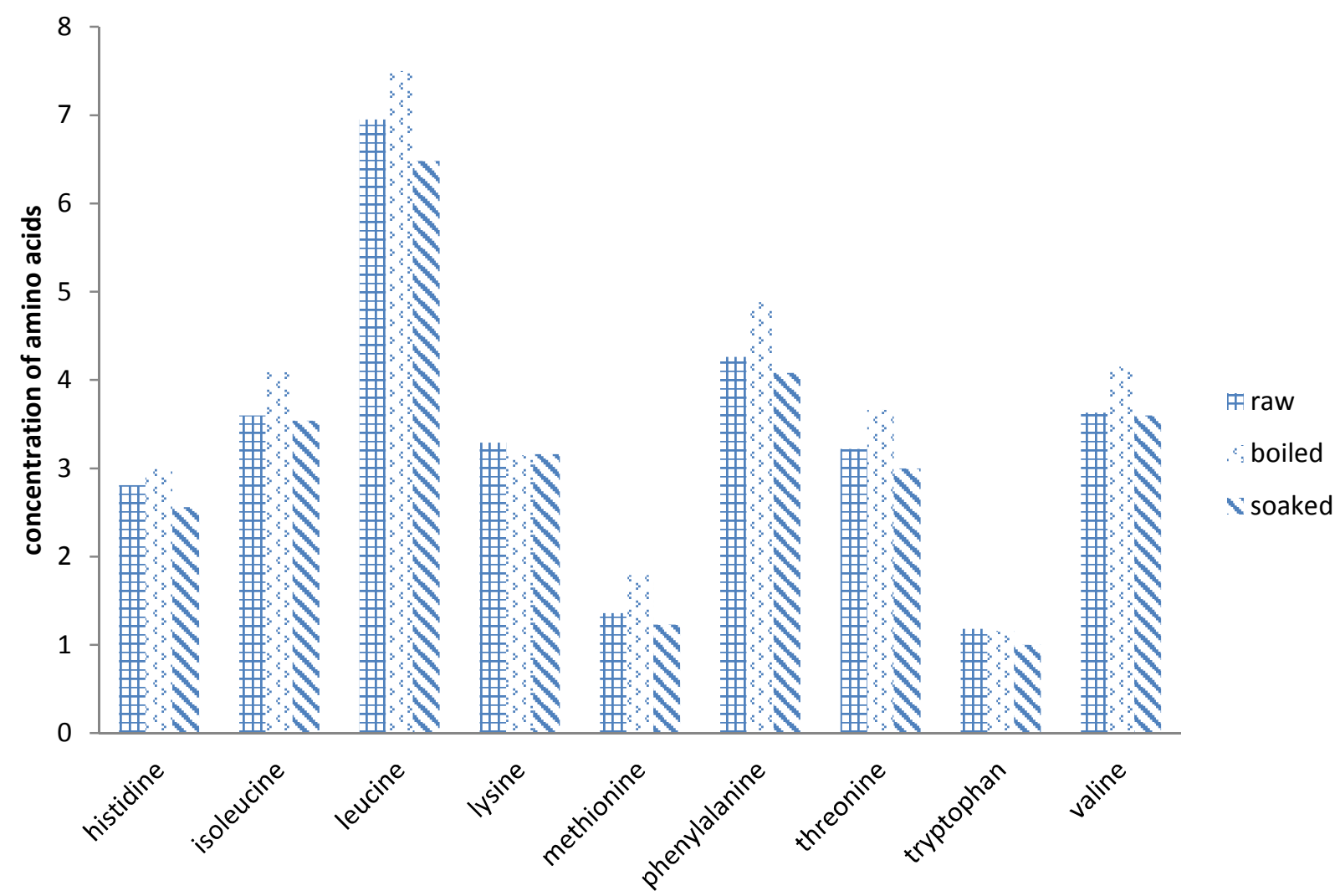

Figure 1: Concentration of essential amino acids in Raw and Processed Balanite aegyptiaca kernel.

Figure 2 shows the concentration of non-essential amino acids in the samples. Soaking had no significant $(\mathrm{P}>0.05)$ effect on the levels of most abundant amino acids (i.e proline, tyrosine, serine, and valine. Glutamic acid and Aspartic acid). However, Boiled sample was found to have the highest concentration of glutamic acids and aspartic acid respectively.

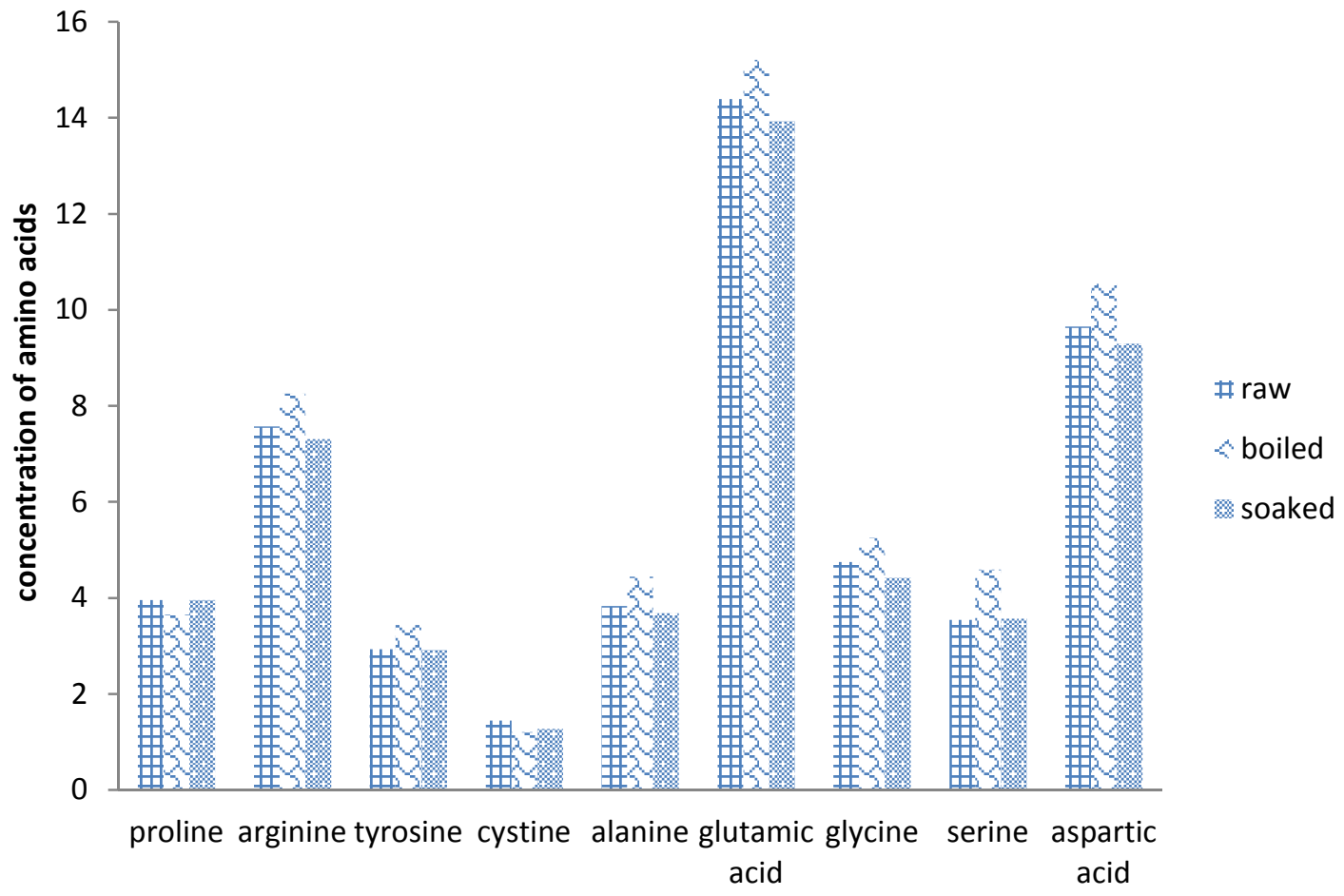

Figure 2: Concentration of non-essential amino acids in raw and processed Balanite aegyptiaca kernel. 


\section{Discussion}

Free amino acids are implicated in secondary plant metabolism and in the production of compounds which directly or indirectly play an important role in the plant environment interaction and in human health (Benitez, 1989). Apart from the fact that free amino acids readily contribute to the nutrient need of the body, they contribute to taste, aroma and colour development of foods. They are precursors for the production of the key flavour compounds and are also precursors of heme, glutathione, various hormones, nucleotides, nucleotide coenzymes, neurotransmitters (Olaofe et al., 1994).

Human bodies do not synthesize the essential amino acids, but can be obtained from food. Ten amino acids are generally regarded as essential for humans: phenylalanine, valine, threonine, tryptophan, isoleucine, methionine, leucine, lysine and histidine which are found to be present in Balanite aegyptiaca kernel (Kuri et al., 1991). Upon boiling, the amino acids concentration amino acid increases. This increase ay be attributed to the destruction of anti-nutritional factors resulting in release of nutrients (Kuri et al., 1991), therefore boiling had more desirable effects on the amino acid composition and should be encouraged as better methods of processing Balanite aegyptiaca kernel for consumption (Kubmarawa et al., 2008).

The non-essential amino acids on the other hand are amino acids that can be produced in our body and they are equally important as the essential amino acids in development of our growth (WHO/FAO/UNU, 1985). For examples, alanine helps in the metabolism of glucose and organic acids while arginine helps to maintain a proper nitrogen balance and aid in the excretion of excess nitrogen. Cysteine and Proline aids in the production of collagen and promotes proper elasticity and texture of the skin, besides reducing the loss of collagen through the aging process (McDougall, 2002).

The relatively higher levels of aspartic acid and glutamic acid with the absence of asparagine and glutamine in this study could be attributed to the hydrolysis of the former to their acids (aspartic acid and glutamic acid respectively) under acidic or basic medium, they might have been present in the kernel protein but converted to their acids (Wathelet and Athelet, 1999).

The significant difference in the value of total amino acid for the raw, soaked and boiled were as follows $(82.37 \mathrm{~g} / 100 \mathrm{~g}, 79.01 \mathrm{~g} / 100 \mathrm{~g}, 89.97 \mathrm{~g} / 100 \mathrm{~g})$, while the value for the total essential amino acids for the raw, soaked and boiled were $(30.30 \mathrm{~g} / 100 \mathrm{~g}, 28.65 \mathrm{~g} / 100 \mathrm{~g}, 33.38 \mathrm{~g} / 100 \mathrm{~g})$ and that for the non-essential were $(52.07 \mathrm{~g} / 100 \mathrm{~g}$, $50.36 \mathrm{~g} / 100 \mathrm{~g}, 56.59 \mathrm{~g} / 100 \mathrm{~g}$ ) respectively. The value for sulphur-containing amino acids (methionine and cystine) for the raw, soaked and boiled samples were $(1.36 \mathrm{~g} / 100 \mathrm{~g}, 1.23 \mathrm{~g} / 100 \mathrm{~g}, 1.79 \mathrm{~g} / 100 \mathrm{~g})$ and the total aromatic amino acid levels (phenylalanine and tyrosine) for the raw, soaked and boiled found in the kernel were $(4.26,4.08,4.88$ and $2.93,2.92$, and $3.44 \mathrm{~g} / 100 \mathrm{~g}$ ) respectively. These data show a variation in free amino acid content between raw, soaked and boiled sample, with boiling method of processing having the highest positive effect on amino acid profile.

\section{Conclusion}

The study revealed that different processing method affects the amino acid profile of Balanites aegyptiaca kernel. Among the two processing method studied, boiling was found to more desirable as it increases the concentration of most amino acids detected in the kernel.

\section{Reference}

AOAC (1997). Official methods of analysis, Association of Official Analytical Chemists, Washington, D.C., USA. 17th Edition, Pp. 807-928.

Benitez LV. (1989). Amino acid and fatty acid profile in aquaculture nutrition studies, p. 23- 35.in S.S. De Silva (ed.) Fish nutrition research in Asia. Proceedings of the third Asian fish nutrition network meeting. Asian Fish Society Special Publication.

Chothani, D.L. and Vaghasiya, H. U. (2011). A Review on Balanites aegyptiaca Del (desert date): Phytochemical constituents, traditional uses, and pharmacological activity. Pharmacogical Review; 5: 55-62.

Clement, A.O., Jacob, G.A., James, M.K., Refaat, A. and Ahmed, A. (2011). Harvesting and Processing of Balanite aegyptiaca Leaves and Fruits for Local Consumption by Rural Communities in Uganda.Journal of Food Technology 9 (2):83-90.

Clement, A.O., Jacob, G.A., James, M.K., Refaat, A. and Ahmed, A. (2011). Harvesting and Processing of Balanite aegyptiaca Leaves and Fruits for Local Consumption by Rural Communities in Uganda. Journal of Food Technology; 9 (2):83-90.

Guinand, Y. and Dechassa, L. (2009). Wild-Food Plants in Southern Ethiopia: Reflections on the role of 'faminefoods' at a time of drought" UN-OCHA Report.

Kubmarawa, D., Andenyang, I.F.H. and Magomya, A.M. (2008). Amino acid profile of two non-convetional leafy vegetables, Sesamum indicum and Balanites aegyptiaca. African Journal of Biotechnology 7 (19): 3502-3504

Kuri, Y.E., Sundar, R.K., Kahuwi, C., Jones, G.P. and Rivett, D.E. (1991). Chemical composition of Momordica charantia L. fruits. Journal of Agricultural and Food chemistry. 39: 1702-1703. 
McDougall J. (2002). Plant foods have a complete amino acid composition. Circulation 105(25):e197.

Muhammad, I. U., Alhassan, A. J., Ramatu, Y., Mohammad, A., Nasir, A., Yaradua, A. I., Alexander, I., Umar Y. and Ezema, M.D. (2018). Amino Acid Profile and Mineral Content of Balanites aegyptiaca Kernel. Asian Journal of Applied Chemistry Research. 1(4): 1-7.

Olaofe, O., Adeyemi, F.O. and Adediran, G.O. (1994). Amino acid and mineral compositions and functional properties of some oil seeds. Journal of Agricultural and Food Chemistry.42: 878-881.

Wathelet B, Athelet B. (1999). Nutritional analysis of proteins and amino acids in beans (Phaseolus spp.). Biotech. Agronomy Soc. Environ. 3:197-200.

WHO/FAO/UNU (1985). Report: Energy and protein requirements: WHO technical report series No.724, pp. 220. 